\title{
Heaven or Hell Faces English Teaching: After Chinese Gaokao Removes English
}

\author{
Y.T. FAN \\ Chongqing Foreign Language School, Chongqing, China
}

Y. LUO

Department of Transfusion Medicine, Southwest Hospital, Third Military Medical University, China

*Corresponding author: Yang Luo, E-mail: luoyang@tmmu.edu.cn

\begin{abstract}
The educational reform policy that English will be removed from Gaokao (College Entrance Examination) in 2017 arouses hot concern from the society. This paper comprehensively analyzes the current situations faced by English teaching, and then comes up with strategies to deal with the existing problems. It is advised that educators should take the right attitude towards the changes in the English exam, and make efforts to improve students' English comprehensive competence. In this way, educators can gradually realize the transition from examination-oriented education to quality education, and promote English teaching cause in China in the long term.
\end{abstract}

KEYWORD: English teaching; Exam reform; Gaokao

\section{INTRODUCTION}

The English examination broke the ice of Gaokao (College entrance examination) reform. On March 1st, 2013, issued by the Ministry of Education, the 1st file "Opinions on the Ministry of Education in 2013 to deepen the comprehensive reform of education" clearly put forward the ideas of taking entrance exam for English subjects several times a year. On May 17, 2014, President of the Chinese Society of Education announced that the country would implement a new program in Gaokao in 2017. English won't be the subject of the college entrance examination, but be changed into social examination. In other words, English examination is no longer included in the basic exam subjects (Chinese and Math), taken in June 7-8th, but be organized by social institutions. Meanwhile, students can choose the test of time within three years of high school, and the grades will be replaced by different levels like CET-4 and CET-6. The signal of the reform is just like a heavy bomb, causing widespread concern and a lot of controversy in the current society(Guo et al.2014,Kirkpatrick et al.2011,Tan et al.2014).

\section{IMPORTANCE AND NECESSITY OF LEARNING ENGLISH}

Some people believe that the removal of English from Gaokao is the progress of Chinese education system, while others hold that this measure can be considered a hell to English teaching (Wyse et al.2013).

\subsection{English is important in pursuing your higher education}

This reform does not mean that students needn't take English exams, but take social exams instead. And the results will be replaced by different levels. For example, some "985" and "211" national key universities would individually set higher admission grades for English, as a matter of fact, their admission thresholds have finally improved. In other words, English is still important in the exam. If you reach a high level, you will have large possibility to be admitted by the university. But if your English level is relatively low, you will miss the dream of entering prestigious universities. Meanwhile, you have to sit for it several times, which will cost more time and considerable efforts(Zhang et al.2013).

As refer to the opinion on the reform, many people think that the policy lays more emphasis on its communication function rather than pursuit of grades. As language normality, the status of English becomes much more important. In 2013, at selfadmission examination of Peking University and Zhejiang University, there is no simple set of English subject, but all the papers are written in English(Chen.2014). In addition, some of these questions need answering in English. Obviously, no one can deny the importance of English. 


\subsection{English is a useful tool in multilateral communication.}

With the rapid progress of economic globalization, English has become an indispensable tool for international communication (Kumaravadivelu. 2013). After all, English is the most prevalent language throughout the world. It is well recognized that most developed economies are predominantly English-speaking countries and $90 \%$ of the countries use English as the official language. Thus most of the reference database use English as the source language in mainstream scientific literature (Shi.2013). "Long-term Educational Reform and Development Plan (2010-2020)," made it clear that promoting internationalization of higher education, training professionals in the field and internationally competitive talents are the purpose for language learners. Therefore, in order to reach the aim and to meet the need of international exchanges, schools should train students to make oral presentations in English, read professional English literature, and master international communication capabilities (Wang et al.2014).

According to the studies by experts of foreign language, only when students' vocabulary is more than 8000, they can meet the basic requirement of professional learning and application. In China, the minimal vocabulary limit in high school graduates is set as 3500 according to the Education administration bureau. Even though, English course is needed in college to help students lay a solid foundation for accelerating further reading. Unfortunately, such minimal limit has been reduced to 3080 words in the newest policy, posing great obstacles to college freshmen because limited vocabulary cannot help their professional learning when reading English materials, and will restrict their professional development to some extent.

Primary and secondary stage is the critical period of language learning. Compared with adults, students of this age group have more advantages when learning foreign languages, like prompt response, active thinking, good memory, little psychological burden, etc., which are favorable conditions for foreign language learning. Furthermore, during the process of learning, students of 8-18 years old can better understand the outside world, absorb advanced scientific and cultural knowledge, enrich cognitive forms, and promote the development of thinking at the same time. In other words, learning English provides them with precious opportunities for future development, which laid a favorable foundation for development. Once missing this special stage, these students are bound to spend more time and effort, but with less return.

\section{STRATEGIES NEEDED TO ENHANCE ENGLISH TEACHING}

Under the baton of the Gaokao for English, high school English education emphasizes high scores instead of English proficiency. Meanwhile, it emphasizes lexical and syntactic explanation rather than the communication function of language. Take reading comprehension for example, many teachers are used to teaching like this: teach grammar, syntax, key language points one by one, but neglecting teaching the structure, main idea, the writing style, and so on. Just like the old saying goes, "be unable to see the wood for the trees." To follow the stream, more and more people in China started to learn English in recent years(Chen et al.2013).

To people's surprise, although plenty of time and money are spent on English, the learning outcome is still unsatisfactory. "China has the largest population in the world to study English, but actually is the least efficient country." According to the report from " EF English Proficiency Index Report " in 2007, the scores from several BRICK countries such as Indonesia, Vietnam and India, and Russia are significantly lower than that of China(Sun et al.2014). But recent report has shown that their scores have already overtaken China. This phenomenon should draw attention from educational authorities. It reveals the fact that English education of high school students cannot be weakened, on the contrary, it has to be strengthened.

On the issue of "what to learn and how to learn English," the exam reform is paving a new way to solve the question. It is reported that the reform tries to solve the problem of English teaching in China from the aspect of examination. This precisely stresses the importance of learning a new language, making it change from the wrong exam-oriented education to quality-oriented education. In addition, it provides students with comprehensive language proficiency training to help them use English fluently and freely.

\subsection{Strategies adopted by school authorities}

Education is the cause of the whole society. Every measure that reforms education system will lead to great concern from society, which can be described as a "butterfly effect". The ultimate goal of the reform is to build a good education mechanism for the whole nation, which can make China become an innovative country with outstanding and international talents.

The reform policy is actually a huge move towards quality education. As we know, quality education is the direction and ultimate goal of educational reform, which is different from the traditional teaching model focusing on exams and grades. As a language, English learning should 
return to the essence of the application and communication, and focus on international thinking, cultural exchanges, social skills, cognitive science, arts, and humanities, which can be employed to improve the self-learning and self-management abilities., Facing the new situation of the reform, the school curriculum should be adjusted to be more in line with the student's learning needs, and comply with the laws of learning English. Meanwhile, in order to improve professional and theoretical level of the teachers, school authorities should allow teachers to have more chances to walk out of school, or out of the country. In this way, teachers can enhance their comprehensive abilities and expand their horizons as well.

\subsection{Strategies adopted by English teachers}

First, English teachers should have a macro view of education. Great importance should be attached to stimulating learning desire for children, helping students to achieve sustainable development, rather than over utilitarian - blind pursuit of scores, or merely take scores as the only criterion for teachers and students. In addition, as English teachers of the front line, they should not be affected by reform policies, but inspired to grasp and absorb the spirit of the reform, and establish the overall outlook of education(Chen et al.2011).

Second, the English teacher should adhere to pragmatic principles. Education must proceed from reality, and take "all for students" as a starting point and ultimate goal. With the rapid development of the world, the language is also undergoing changes. Thus English teachers, must advance with the times, teaching basic knowledge of the language, spreading foreign cultures and customs, helping students can "select the refined and discard the crude". Third, the professional development of English teachers should be promoted. As front-line teachers, they must maintain an optimistic and positive attitude, besides, they should stick to lifelong learning, cultivating and developing rigorous scientific spirit. For practical problems arising from current education, teachers seem to deal with them timely and properly. Therefore, recording teaching reflection or sharing teaching philosophy and teaching methods in time can definitely promote the entire group and education field as a whole.

Fourth, fully mobilize the initiative of students. With the reform of Gaokao, enthusiasm of learning English for students may decline day by day. How to mobilize the enthusiasm and initiative of the students is the first question for teachers. Once the "sea tactical" has to be abandoned, instead, teachers should show a lively and interesting English class for students(Hu et al.2014). On the other hand, teachers should also adopt stratified teaching method for different levels of the student. In the teaching process, teachers can fully stimulate students' enthusiasm of learning, vigorously carry out quality education, and help students learn deeper and better.

\subsection{Strategies adopted by parents and students}

The reform policy is a "to retreat" initiative. Actually, the so-called "to retreat" pays much attention to the practical and communicative functions of English. in view of this, the students can set reasonable goals according to their actual situation. When foreign language learning is no longer for test, but to meet actual demands, then it can better highlight its importance and practical value.

The entrance examination is undergoing changes. In the English exam in the future, much easier questions will appear. Exams are getting easier, so if students with good psychological quality are careful enough, they can get good grades.. For some good students, they'd better read some short articles, listen to recordings, and seek opportunities to practice speaking with their classmates. for some ordinary students, they can just master key points taught by teachers, and communicate with others in English. In the meantime, parents should actively cooperate with teachers, insisting on "learning by doing" principle, so that students can gradually improve comprehensive language ability.

\section{CONCLUSION}

Language skills often form in a relatively long-term process of accumulation, practice, and application. The learning philosophy of Modern language emphasizes that language learning should focus on learning outcomes, but on the learning process. Language learning emphasizes practice and application. These two characteristics determine that languages cannot be mastered by mechanical recitation and explanation, but need great efforts and efficient learning strategies. Therefore, we should allow students to become masters of learning. Parents and teachers should adhere to the principle of edutainment, to encourage students to improve reading and writing skills. China's education has entered an era of big changes, so various types of trial and innovation may frequently occur. In order to reduce the negative impact of such change, educators should lead children to a road in accordance with the study rules and regulations. English is a tool to communicate with people around the world and a link between the countries in the world. Students with good English are bound to benefit lifetime. Nevertheless, Parents and students should take the right attitude towards the changes in the English exam, not be influenced by any change of the policy to hit enthusiasm and initiative of the students. 


\section{REFERENCES}

[1] Chen Q, May L, et al. 2013. The enactment of formative assessment in English language classrooms in two Chinese universities: teacher and student responses. Assessment in Education: Principles, Policy \& Practice: 1-15.

[2] Chen Y. Reflections on Educational Inequality and Its Countermeasures; 2014. Atlantis Press.

[3] Chen Z, Goh C. 2011. Teaching oral English in higher education: Challenges to EFL teachers. Teaching in Higher Education 16: 333-345.

[4] Guo X, Zhao W, et al. 2014. Strategies for innovative education reform in China's institutions of higher learning. Journal of Chemical and Pharmaceutical Research 6: 2600-2605.

[5] Hu G, Lei J. 2014. English-medium instruction in Chinese higher education: a case study. Higher Education 67: 551567.

[6] Kirkpatrick R, Zang Y. 2011. The negative influences of exam-oriented education on Chinese high school students: Backwash from classroom to child. Language Testing in Asia 1: 36.

[7] Kumaravadivelu B. 2013. Rethinking Global Perspectives and Local Initiatives in Language Teaching. Language
Teachers and Teaching: Global Perspectives, Local Initiatives 98: 317.

[8] Shi X. 2013. The Glocalization of English A Chinese Case Study. Journal of Developing Societies 29: 89-122.

[9] Sun Z, Qiu X. 2014. Evaluating the use of wikis for EFL: a case study of an undergraduate English writing course in China. International Journal of Information Technology and Management 13: 3-14.

[10] Tan C, Chua CS. 2014. Education policy borrowing in China: has the West wind overpowered the East wind? Compare: A Journal of Comparative and International Education: 1-19.

[11] Wang F, Clarke A. 2014. The practicum experiences of English Language Major student teachers during a period of profound curriculum reform in China. International Journal of Educational Development 36: 108-116.

[12] Wyse D, Jones R, et al., editors 2013 Teaching English, language and literacy. Second Edition: Routledge.

[13] Zhang Q-M, Kim T-Y. 2013. Cross-grade analysis of Chinese students' English learning motivation: a mixedmethods study. Asia Pacific Education Review 14: 615627. 